\title{
Negatively Curved Nanographene with Heptagonal and [5]Helicene Units
}

Zijie Qiu, Sobi Asako,* Yunbin Hu, Cheng-Wei Ju, Thomas Liu, Loïc Rondin, Dieter Schollmeyer, Jean-Sébastien Lauret, Klaus Müllen,* and Akimitsu Narita*

Cite This: J. Am. Chem. Soc. 2020, 142, 14814-14819

Read Online

ABSTRACT: Negatively curved nanographene (NG) 4, having two heptagons and a [5] helicene, was unexpectedly obtained by aryl rearrangement and stepwise cyclodehydrogenations. X-ray crystallography confirmed the saddle-shaped structures of intermediate 3 and NG 4. The favorability of rearrangement over helicene formation following radical cation or arenium cation mechanisms is supported by theoretical calculations. NG 4 demonstrates a reversible mechanochromic color change and solid-state emission, presumably benefiting from its loose crystal packing. After resolution by chiral high-performance liquid chromatography, the circular dichroism spectra of enantiomers $4-(P)$ and 4- $(M)$ were measured and showed moderate Cotton effects at $350 \mathrm{~nm}\left(|\Delta \varepsilon|=148 \mathrm{M}^{-1}\right.$ $\left.\mathrm{cm}^{-1}\right)$.

$\mathrm{C}$ urved nanographenes (NGs), obtained by incorporating nonhexagonal rings into the "honeycomb" framework, have become exciting targets in different scientific fields. ${ }^{1-4}$ The resulting surfaces, which can be classified as having positive or negative Gaussian curvatures, furnish NGs with unique properties. ${ }^{1}$ NGs containing pentagons have positive curvature and possess bowl-shaped structures. Thus, corannulene-based NGs can be considered as subunits of fullerene, ${ }^{5,6}$ and they have been used as caps in the chemical synthesis of carbon nanotubes; ${ }^{7}$ bischrysenyl molecules with fused pentagons exist as stable open-shell singlet biradicals and hold promise for quantum computing. 8,9

On the other hand, seven- or eight-membered rings induce negative curvature. Saddle-shaped NGs containing heptagons often demonstrate dynamic stereochemistry, which can lead to fluorescence quenching in solution. ${ }^{10}$ Moreover, the syntheses and studies of heptagon-incorporating NGs could stimulate the investigation of elusive carbon nanostructures, such as carbon schwarzites and Mackay crystals. ${ }^{11-14}$ Compared with their positively curved counterparts, negatively curved NGs with heptagons are rare and deserve more attention.

The first reported heptagon-embedded NG, [7] circulene was achieved by Yamamoto in 1983 by intramolecular photocyclization and reductive coupling. ${ }^{15,16}$ Since then, several methods to construct seven-membered carbocycles, including ring expansion, ${ }^{17,18}$ cyclotrimerization, ${ }^{19}$ and intramolecular cyclization, ${ }^{20-26}$ have been developed. Among these bottom-up approaches, multiple intramolecular cyclizations by the Scholl reaction are particularly powerful, as demonstrated by the grossly warped NG reported by Scott and Itami. ${ }^{27}$ However, the outcome of the Scholl reaction is sometimes surprising, even counterintuitive, since it can be accompanied by migrations and rearrangement processes. ${ }^{28-32}$

During our attempts at synthesizing $\pi$-extended [7] helicene 2 through the oxidative cyclodehydrogenation of precursor $\mathbf{1}$, we unexpectedly obtained a negatively curved NG 4 with two seven-membered rings and a [5] helicene substructure through an aryl rearrangement and cyclodehydrogenation sequence (Scheme 1). The structures of both intermediate 3 and final NG 4 were unambiguously identified by X-ray crystallography analysis. Density functional theory (DFT) calculations revealed that rearrangement via spiro-ring formation was favored over helicene formation by either radical cation or arenium cation mechanism. NG 4 is fluorescent in the solution and solid states and demonstrated a reversible change in color and emission between crystalline and amorphous powders, presumably due to its loose crystal packing. Because of the incorporation of heptagons and a [5]helicene, NG 4 was twisted into a saddleshaped curvature with an experimental isomerization barrier of $25.4 \mathrm{kcal} \mathrm{mol}^{-1}$, enabling the separation of its enantiomers by high-performance liquid chromatography (HPLC) with a chiral column and subsequent circular dichroism (CD) measurements.

3',6'-Bis(naphthylphenyl)-o-terphenyl precursor (1) was synthesized in four steps on a gram scale (Scheme 1). Starting from 2,3-dibromo-1,4-bis(trimethylsilyl)benzene (5), $3^{\prime}, 6^{\prime}$ diiodo-o-terphenyl derivative 7 could be obtained by Suzuki coupling and iodination in high yields as adapted from our previous procedure. ${ }^{33}$ The selective Suzuki coupling of 7 and 2-bromophenylboronic acid produced $3^{\prime}, 6^{\prime}$-bis (2-bromophenyl)-o-terphenyl compound $\mathbf{8}$ in $80 \%$ yield. Precursor $\mathbf{1}$ was then obtained by the Suzuki coupling of 8 and 2naphthylboronic acid in $88 \%$ yield. Precursor 1 was subsequently subjected to oxidative cyclodehydrogenation

Received: May 19, 2020

Published: August 18, 2020 
Scheme 1. Synthetic Route towards Negatively Curved NG 4
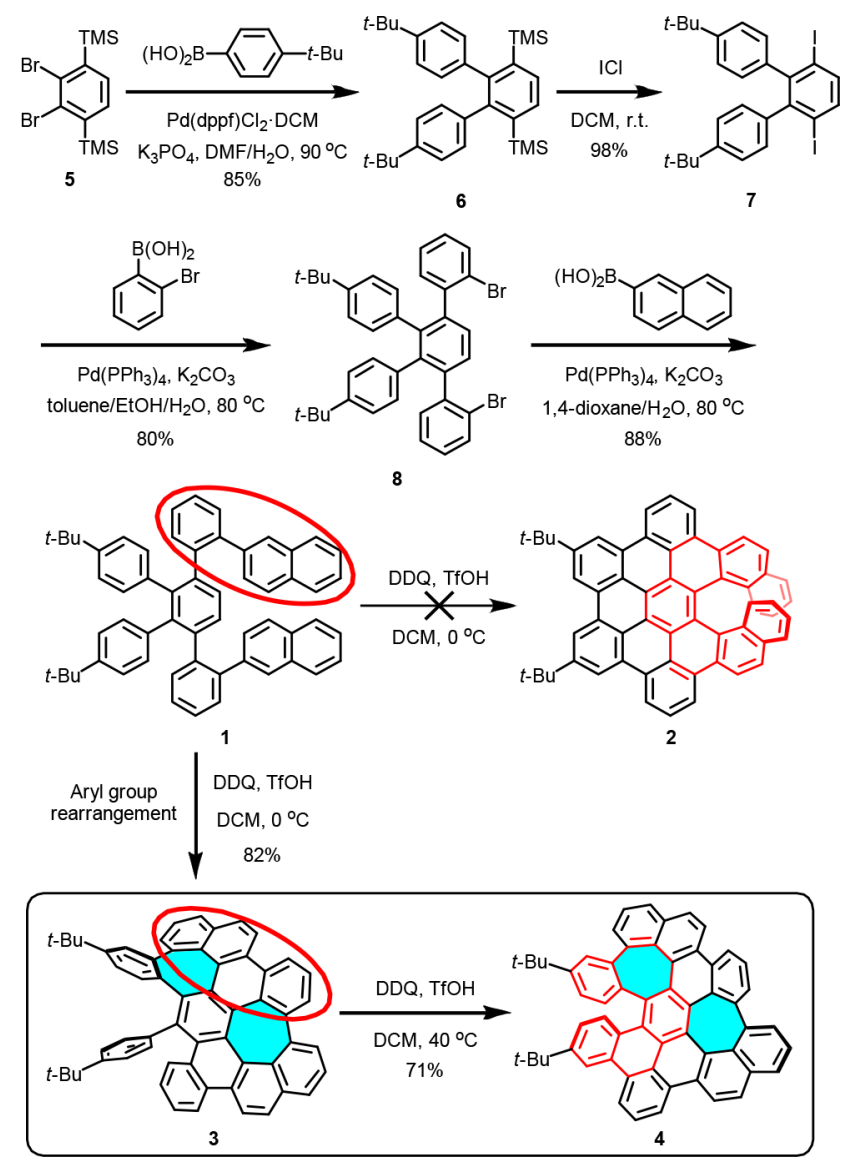

with 2,3-dichloro-5,6-dicyano-1,4-benzoquinone (DDQ) and trifluoromethanesulfonic acid $(\mathrm{TfOH})$ in dry dichloromethane (DCM) at $0{ }^{\circ} \mathrm{C}$ under argon, which after $20 \mathrm{~min}$, provided compound 3 in $82 \%$ yield. Matrix-assisted laser desorption/ ionization-time-of-flight (MALDI-TOF) mass spectrometry (MS) analysis of 3 exhibited an intense signal at $\mathrm{m} / \mathrm{z}=$ 738.32 (Figure $\mathrm{S} 11$, calculated value for $\mathrm{C}_{58} \mathrm{H}_{42}$ : 738.33), indicating 3 to be an intermediate with two more hydrogens than target product 2 .

Further reacting intermediate 3 with $\mathrm{DDQ} / \mathrm{TfOH}$ in dry $\mathrm{DCM}$ at $40{ }^{\circ} \mathrm{C}$ under argon furnished product 4 in $71 \%$ yield. MALDI-TOF MS analysis of $\mathbf{4}$ displayed an intense signal at $m / z=736.31$ (Figure S14, calculated value for $\mathrm{C}_{58} \mathrm{H}_{40}$ : 736.31). Although this mass is the same as that of $\pi$-extended [7] helicene 2, the ${ }^{1} \mathrm{H}$ and ${ }^{13} \mathrm{C}$ NMR spectra of 4 suggested a highly unsymmetrical structure (Figures S15-S16).

Crystals of 1, 3, and 4 suitable for single-crystal analyses by $\mathrm{X}$-ray diffraction could be obtained by slow diffusion of ethanol into their chloroform or dichloromethane solutions (Figures 1A-C, S21-S22). Excitingly, NG 4 revealed a unique structure with two heptagons as well as a [5] helicene (marked by black arrows in Figure 1A) with a torsion angle of $35.2^{\circ}$ (atoms 1-2-3-4). Due to the two heptagonal subunits, NG 4 was negatively curved into a saddle shape with out-of-plane deformed benzenoid rings (Figure 1B). This saddle was $9.79 \AA$ wide and $3.36 \AA$ deep from the upper part, while it was $9.31 \AA$ wide and $2.79 \AA$ deep from the lower part. $P / M$ enantiomers of 4, denoted 4- $(P)$ and 4- $(M)$ (highlighted in blue and red, respectively), were observed, and they stacked in an alternating
(A)
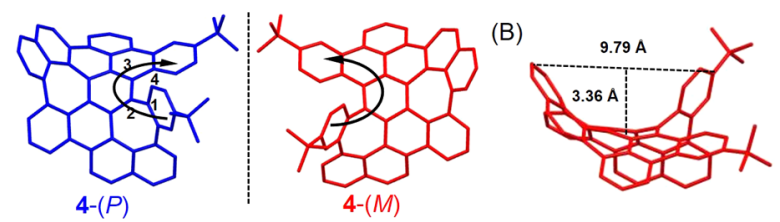

(C)

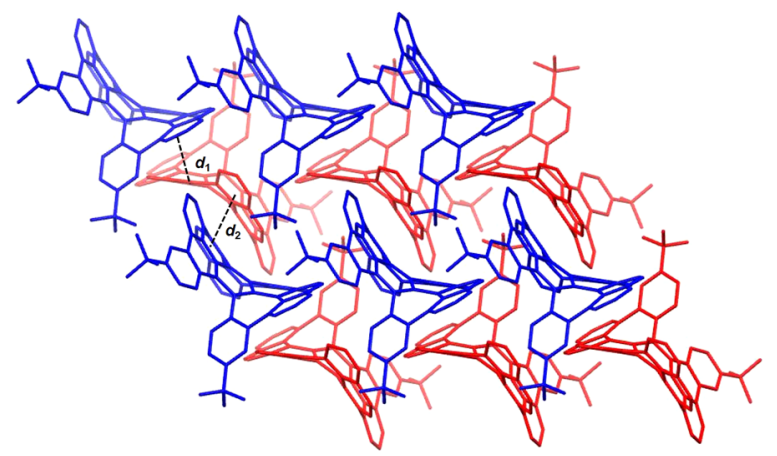

(D)

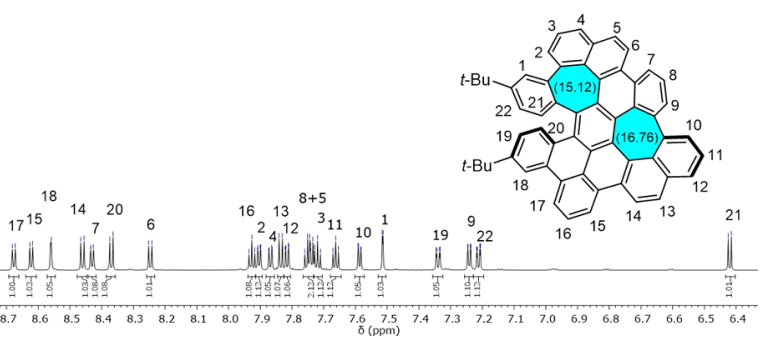

Figure 1. (A-C) Single-crystal structures of 4-(P) and 4-(M). (B) Side view of 4-(M). (C) Molecular packing of 4. All hydrogen atoms are omitted for clarity. (D) Aromatic region of the ${ }^{1} \mathrm{H}$ NMR spectrum of 4 with proton peak assignments $\left(850 \mathrm{MHz}, \mathrm{C}_{2} \mathrm{D}_{2} \mathrm{Cl}_{4}\right)$ and $\operatorname{NICS}(1)_{z z}$ values (in ppm in parentheses) of two heptagons.

manner to form pairs of enantiomers (Figure 1C). The intermolecular distances of the $P / M$ enantiomer pairs were measured as $d_{1}=3.90 \AA$ and $d_{2}=3.83 \AA$, suggesting that 4 was loosely packed, reflecting its highly twisted structure.

Assisted by its crystal structure, 2D NMR analyses, and simulated ${ }^{1} \mathrm{H}$ NMR spectrum (Figures S17-S20), all the aromatic proton peaks in the ${ }^{1} \mathrm{H}$ NMR spectrum of NG 4 were assigned (Figure 1D). Notably, while the chemical shift of proton 20 was still at $8.37 \mathrm{ppm}$, the signal of proton 21 was shifted upfield to $6.42 \mathrm{ppm}$. This was in line with the shielding effect expected from the curved surface. Nucleus-independent chemical shift (NICS) calculations of NG 4 at the GIAOB3LYP/6-311G (d,p) level (Figure S36) ${ }^{34-36}$ revealed negative values ranging from -3.41 to $-26.88 \mathrm{ppm}$ for all the benzene rings. In contrast, the two heptagons showed positive values of 15.12 and $16.76 \mathrm{ppm}$ (Figure 1D), indicating their antiaromaticity, ${ }^{37,38}$ which might also account for the upfield shift of proton 21 adjacent to a heptagon.

To understand the rearrangement during the cyclodehydrogenation of precursor 1 leading to NG 4 instead of $\pi$ extended helicene 2, DFT calculations were performed at the (U) $\omega$ B97X-D/6-31+G(d,p)//(U) $\omega$ B97X-D/6-31G(d) level of theory using the SMD solvation model with DCM. According to the literature, ${ }^{29,39,40}$ two possible intermediates, radical cation $\mathbf{R} \mathbf{1}$ and arenium cation A1, were proposed for the key step for comparing the energy barriers in the "rearrangement" and "helicene" pathways. Radical cation intermediate $\mathbf{R} 1$ can undergo $\mathrm{C}-\mathrm{C}$ bond formation at either the ipso or ortho position of the central benzene ring, with respect to a naphthylphenyl group (Scheme $2 \mathrm{~A}$ ). The $\mathrm{C}-\mathrm{C}_{\text {ipso }}$ 
Scheme 2. Proposed Reaction Mechanisms for the Rearrangement during the Scholl Reaction via (A) Radical Cation or (B) Arenium Cation Intermediates. Gibbs Free Energies and Enthalpies (Italicized) are Given in $\mathrm{kcal} / \mathrm{mol}^{a}$

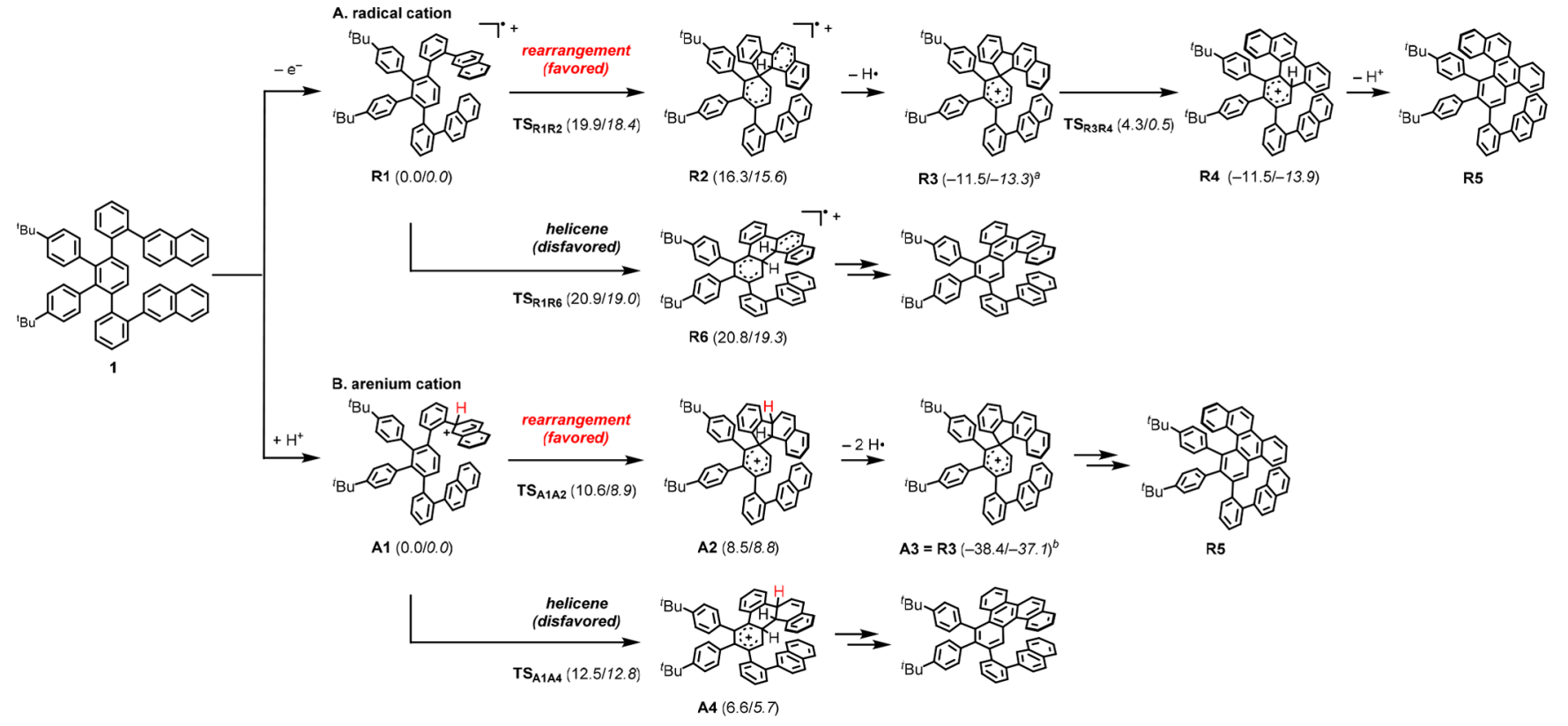

${ }^{a} \mathrm{DDQ}^{\bullet-}$ as an $\mathrm{H}$ atom acceptor. ${ }^{b} \mathrm{DDQ}$ as an oxidant.

bond formation leading to spiro intermediate $\mathbf{R} \mathbf{2}$ was found to proceed through a transition state (TS) with a lower energy $\left(\mathrm{TS}_{\mathrm{R} 1 \mathrm{R} 2}=19.9 \mathrm{kcal} / \mathrm{mol}\right)$ than that toward $\mathbf{R} 6$ by $\mathrm{C}-\mathrm{C}_{\text {ortho }}$ bond formation $\left(\mathrm{TS}_{\mathrm{R} 1 \mathrm{R} 6}=20.9 \mathrm{kcal} / \mathrm{mol}\right)$. Subsequent $\mathrm{H}$ atom abstraction (R3), 1,2-migration of the phenyl group (R4), and deprotonation afforded rearranged intermediated $\mathrm{R} 5$ with the formation of a new $\mathrm{C}-\mathrm{C}$ bond. R5 could undergo further dehydrogenative couplings to afford 3 and 4 . This mechanism is analogous to that involving a 1,2-aryl migration in the oxidative coupling of tetraarylpyrrolopyrroles. ${ }^{41}$ Similarly, the energy barriers were also calculated through arenium intermediate A1, and the rearrangement was again more favorable than helicene formation (Scheme 2B). The possible mechanisms involving arenium cation intermediates with protonation on the central benzene ring were excluded due to higher energies in transition states (Figure S35 for more details). Therefore, the rearrangement occurs in the first step of the dehydrogenation and is favored over helicene formation in both the radical cation and arenium cation mechanisms.

While the absorption spectrum of 3 exhibited a maximum $\left(\lambda_{\mathrm{abs}}\right)$ at $380 \mathrm{~nm}$, the $\lambda_{\mathrm{abs}}$ of 4 was red shifted to $392 \mathrm{~nm}$, in agreement with its extended $\pi$-conjugation (Figure S23). Notably, both 3 and 4 featured large Stokes shifts ( 0.89 and $1.13 \mathrm{eV})$, showing green and orange-red fluorescence with emission maxima of 522 and $611 \mathrm{~nm}$, respectively. Such large Stokes shifts and broad emission bands were attributed to their conformational flexibility in solution, ${ }^{10}$ which could also account for their relatively low quantum yields in solution (3: $5 \%$; $4: 11 \%$ ). Further details for the emission properties of 4, including the aggregation-caused quenching of fluorescence, concentration and solvent dependence of the spectra, as well as an emission lifetime measurement, are reported in Figures S24-S28. The electrochemical properties of $\mathbf{3}$ and $\mathbf{4}$ were studied by cyclic voltammetry in DCM solutions with ferrocene as an external standard, and the highest occupied molecular orbital (HOMO) energy levels of $\mathbf{3}$ and $\mathbf{4}$ were estimated to be 5.32 and $5.17 \mathrm{eV}$, respectively (Figure S29), consistent with the DFT calculations (Figure S37). The HOMO-LUMO (lowest unoccupied molecular orbital) gaps of 3 and 4 were calculated to be 3.22 and $3.02 \mathrm{eV}$, respectively.

Interestingly, when the DCM was evaporated from the NG 4 solution, a nanocrystalline powder was formed, displaying yellow fluorescence with an emission peak at $550 \mathrm{~nm}$ (Figure 2A). Inspired by its loose crystal packing and structural
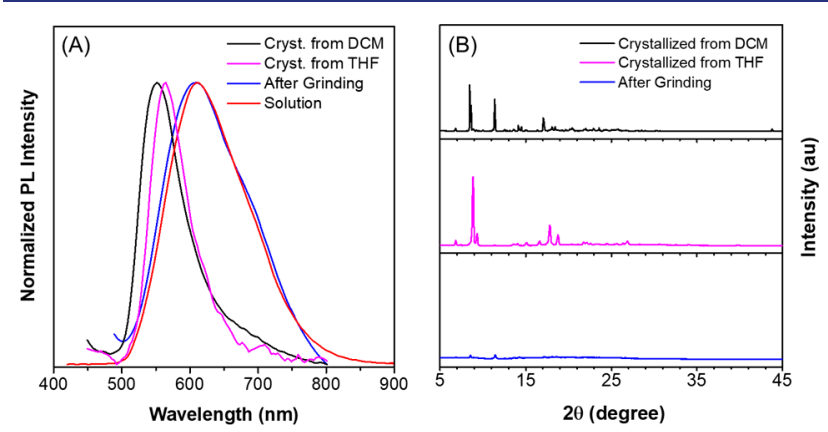

Figure 2. (A) Emission spectra of 4 in solution and different solid states, showing a mechanochromic behavior. Solution concentration: $10 \mu \mathrm{M}$. (B) Powder XRD analyses of 4 in different solid states.

flexibility, the mechanochromic behavior ${ }^{42}$ of 4 was explored. When the nanocrystalline powder of 4 obtained from DCM was ground into an amorphous powder, the emission peak was red shifted to $610 \mathrm{~nm}$, which was almost identical to that in solution. The amorphous powder could be transformed into yellow nanocrystals by treatment with DCM vapor for $10 \mathrm{~min}$. This grinding-fuming sequence could be reversibly repeated for 5 cycles without obvious fatigue (Figure S30). Notably, 4 formed a slightly different crystal when crystallized from THF solution, showing an emission peak at $565 \mathrm{~nm}$. The shifting of emission wavelength was caused by the presence of solvent molecules, which was confirmed by the $\mathrm{X}$-ray analysis (Figure 
S31, CCDC: 2021692). These results indicated that the mechanochromic behavior of $\mathbf{4}$ was caused by different molecular packing modes in the solid states, which was also supported by different diffraction patterns in powder X-ray diffraction (PXRD) measurements (Figure 2B). Such reversible mechanochromic behavior is unusual in curved nanographenes with only fused hydrocarbons, ${ }^{43,44}$ suggesting potential applications of $\mathbf{4}$ in mechanosensors, security papers, optical storage, etc. ${ }^{45,46}$

The isomerization barrier between $4-(P)$ and 4- $(M)$ was calculated by DFT to be $26.1 \mathrm{kcal} \mathrm{mol}^{-1}$ (Figure $3 \mathrm{~A}$ ) and
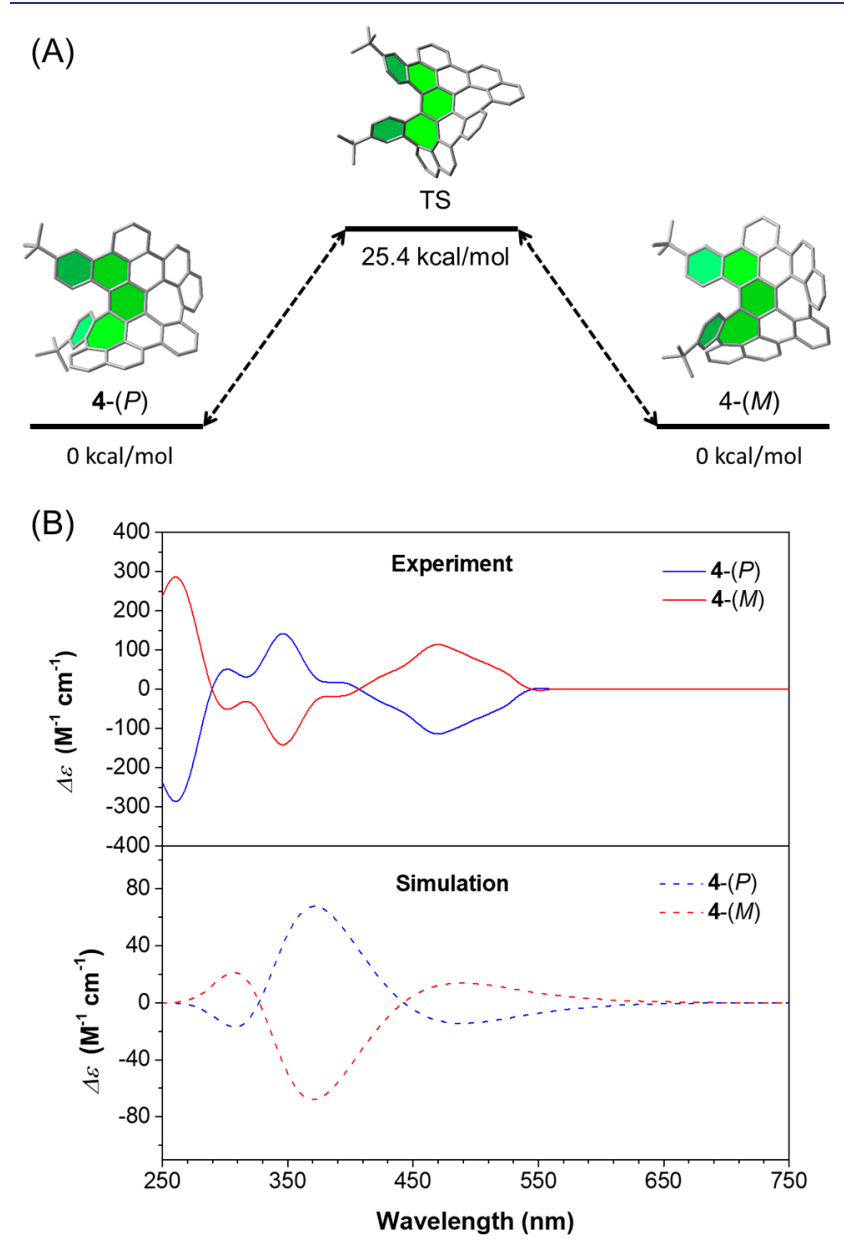

Figure 3. (A) Isomerization between 4- $(P)$ and 4- $(M)$. All hydrogen atoms were omitted for clarity. (B) Experimental (solid lines) and TD-DFT simulated (dashed lines) CD spectra of $4-(P)$ and $4-(M)$.

experimentally determined as $25.4 \mathrm{kcal} \mathrm{mol}^{-1}$ (Figures S32S33), which was higher than those of previously reported heptagon-bearing $\mathrm{NGs}^{17,18,22,27}$ but similar to other [5]carbohelicenes. $^{47-50} 4-(P)$ and 4- $(M)$ could indeed be separated by chiral HPLC (Figure S34). CD spectra of the first HPLC fraction demonstrated a negative Cotton effect at $350 \mathrm{~nm}$ with a moderate value $\left(|\Delta \varepsilon|=148 \mathrm{M}^{-1} \mathrm{~cm}^{-1}\right)$, while the enantiomer that eluted second displayed a mirror image CD curve with a positive Cotton effect, which was in good agreement with the simulated spectra calculated by timedependent DFT (TD-DFT) (Figure 3B). The first and second HPLC fraction could thus be assigned to $4-(M)$ and 4- $(P)$, respectively. The hole-electron analysis of the major transitions ${ }^{36,51}$ (first, second, and ninth excited states in
Figures S38-S39) suggest that the CD signal at $>450 \mathrm{~nm}$ can be attributed to the twisted $\pi$-backbone of the whole molecule, while the configuration of [5] helicene structure is more related to the CD signal at $350 \mathrm{~nm}$.

In summary, the oxidative cyclodehydrogenation of precursor 1 provided unprecedented NG 4 with a negative curvature through an aryl rearrangement, which was unambiguously revealed by X-ray crystallography. With two heptagonal and one [5] helicene substructure, NG 4 was highly twisted into a saddle shape with two enantiomers, 4- $(P)$ and 4$(M)$, which could be resolved by chiral HPLC. According to theoretical studies, the energy barriers of the rearrangement pathways are lower than those for helicene formation in both the radical cation and arenium cation mechanisms, rationalizing the experimental results. The unexpected rearrangement observed in this study has inspired us to systematically investigate the Scholl reactions of related precursors. Moreover, it facilitates the design of modified precursors leading to $\pi$-extended helicenes and other curved NGs in subsequent studies.

\section{ASSOCIATED CONTENT}

\section{Supporting Information}

The Supporting Information is available free of charge at https://pubs.acs.org/doi/10.1021/jacs.0c05504.

Experimental details, characterization spectra, singlecrystal data, photophysical and electrochemical measurements, as well as computational details (PDF)

Crystallographic data for 1, 3, and 4-DCM (CIF)

Crystallographic data for 4-THF (CIF)

\section{AUTHOR INFORMATION}

\section{Corresponding Authors}

Sobi Asako - RIKEN Center for Sustainable Resource Science, Wako, Saitama 351-0198, Japan; 이이.org/0000-00034525-5317; Email: sobi.asako@riken.jp

Klaus Müllen - Max Planck Institute for Polymer Research, 55128 Mainz, Germany; Department of Chemistry, University of Cologne, 50939 Cologne, Germany; 이이.org/00000001-6630-8786; Email: muellen@mpip-mainz.mpg.de

Akimitsu Narita - Max Planck Institute for Polymer Research, 55128 Mainz, Germany; Organic and Carbon Nanomaterials Unit, Okinawa Institute of Science and Technology Graduate University, Kunigami-gun, Okinawa 904-0495, Japan; Email: akimitsu.narita@oist.jp

\section{Authors}

Zijie Qiu - Max Planck Institute for Polymer Research, 55128 Mainz, Germany; 이이.org/0000-0003-0728-1178

Yunbin Hu - Max Planck Institute for Polymer Research, 55128 Mainz, Germany; (1) orcid.org/0000-0001-5346-7059

Cheng-Wei Ju - Max Planck Institute for Polymer Research, 55128 Mainz, Germany; College of Chemistry, Nankai University, Tianjin 300071, China; (1) orcid.org/0000-00022250-8548

Thomas Liu - Universite Paris Saclay, ENS Paris Saclay, Centrale Supelec, CNRS, LUMIN, 91405 Orsay Cedex, France

Loïc Rondin - Université Paris Saclay, ENS Paris Saclay, Centrale Supelec, CNRS, LUMIN, 91405 Orsay Cedex, France

Dieter Schollmeyer - Department of Chemistry, Johannes Gutenberg-University Mainz, 55099 Mainz, Germany 
Jean-Sébastien Lauret - Université Paris Saclay, ENS Paris Saclay, Centrale Supelec, CNRS, LUMIN, 91405 Orsay Cedex, France; (1) orcid.org/0000-0003-1309-4977

Complete contact information is available at: https://pubs.acs.org/10.1021/jacs.0c05504

\section{Notes}

The authors declare no competing financial interest.

\section{ACKNOWLEDGMENTS}

This work was financially supported by the Max Planck Society, the Fund of Scientific Research Flanders (FWO) under EOS 30489208, the FLAG-ERA Grant OPERA by DFG 437130745 and ANR-19-GRF1-0002-01, the ANR-DFG NLE Grant GRANAO by DFG 431450789 and ANR-19-CE090031-01, and the Alexander von Humboldt Foundation. The generous amount of computational time provided by the Research Center for Computational Science, Okazaki, Japan, is gratefully acknowledged. This paper is dedicated to Professor Eiichi Nakamura on the occasion of his 70th birthday.

\section{REFERENCES}

(1) Pun, S. H.; Miao, Q. Toward negatively curved carbons. Acc. Chem. Res. 2018, 51, 1630-1642.

(2) Marquez, I. R.; Castro-Fernandez, S.; Millan, A.; Campana, A. G. Synthesis of distorted nanographenes containing seven- and eightmembered carbocycles. Chem. Commun. 2018, 54, 6705-6718.

(3) Majewski, M. A.; Stepien, M. Bowls, hoops, and saddles: synthetic approaches to curved aromatic molecules. Angew. Chem., Int. Ed. 2019, 58, 86-116.

(4) Rickhaus, M.; Mayor, M.; Juricek, M. Chirality in curved polyaromatic systems. Chem. Soc. Rev. 2017, 46, 1643-1660.

(5) Dorel, R.; de Mendoza, P.; Calleja, P.; Pascual, S.; GonzalezCantalapiedra, E.; Cabello, N.; Echavarren, A. M. Synthesis of a crushed fullerene $\mathrm{C} 60 \mathrm{H} 24$ through sixfold palladium-catalyzed arylation. Eur. J. Org. Chem. 2016, 2016, 3171-3176.

(6) Otero, G.; Biddau, G.; Sanchez-Sanchez, C.; Caillard, R.; Lopez, M. F.; Rogero, C.; Palomares, F. J.; Cabello, N.; Basanta, M. A.; Ortega, J.; Mendez, J.; Echavarren, A. M.; Perez, R.; Gomez-Lor, B.; Martin-Gago, J. A. Fullerenes from aromatic precursors by surfacecatalysed cyclodehydrogenation. Nature 2008, 454, 865-868.

(7) Scott, L. T.; Jackson, E. A.; Zhang, Q.; Steinberg, B. D.; Bancu, M.; Li, B. A short, rigid, structurally pure carbon nanotube by stepwise chemical synthesis. J. Am. Chem. Soc. 2012, 134, 107-110.

(8) Ma, J.; Liu, J.; Baumgarten, M.; Fu, Y.; Tan, Y. Z.; Schellhammer, K. S.; Ortmann, F.; Cuniberti, G.; Komber, H.; Berger, R.; Müllen, K.; Feng, X. A stable saddle-shaped polycyclic hydrocarbon with an openshell singlet ground state. Angew. Chem., Int. Ed. 2017, 56, 32803284.

(9) Lombardi, F.; Lodi, A.; Ma, J.; Liu, J.; Slota, M.; Narita, A.; Myers, W. K.; Müllen, K.; Feng, X.; Bogani, L. Quantum units from the topological engineering of molecular graphenoids. Science 2019, 366, 1107-1110.

(10) Cheung, K. Y.; Xu, X.; Miao, Q. Aromatic saddles containing two heptagons. J. Am. Chem. Soc. 2015, 137, 3910-3914.

(11) Lenosky, T.; Gonze, X.; Teter, M.; Elser, V. Energetics of negatively curved graphitic carbon. Nature 1992, 355, 333-335.

(12) Mackay, A. L.; Terrones, H. Diamond from graphite. Nature 1991, 352, 762.

(13) Park, S.; Kittimanapun, K.; Ahn, J. S.; Kwon, Y. K.; Tomanek, D. Designing rigid carbon foams. J. Phys.: Condens. Matter 2010, 22, 334220 .

(14) Park, N.; Yoon, M.; Berber, S.; Ihm, J.; Osawa, E.; Tomanek, D. Magnetism in all-carbon nanostructures with negative Gaussian curvature. Phys. Rev. Lett. 2003, 91, 237204.
(15) Yamamoto, K.; Harada, T.; Nakazaki, M. Synthesis and characterization of [7]circulene. J. Am. Chem. Soc. 1983, 105, 71717172.

(16) Yamamoto, K.; Harada, T.; Okamoto, Y.; Chikamatsu, H.; Nakazaki, M.; Kai, Y.; Nakao, T.; Tanaka, M.; Harada, S.; Kasai, N. Synthesis and molecular structure of [7]circulene. J. Am. Chem. Soc. 1988, 110, 3578-3584.

(17) Pun, S. H.; Chan, C. K.; Luo, J.; Liu, Z.; Miao, Q. A dipleiadiene-embedded aromatic saddle consisting of 86 carbon atoms. Angew. Chem., Int. Ed. 2018, 57, 1581-1586.

(18) Pun, S. H.; Wang, Y.; Chu, M.; Chan, C. K.; Li, Y.; Liu, Z.; Miao, Q. Synthesis, Structures, and Properties of Heptabenzo[7]circulene and Octabenzo[8]circulene. J. Am. Chem. Soc. 2019, 141, 9680-9686.

(19) Marquez, I. R.; Fuentes, N.; Cruz, C. M.; Puente-Munoz, V.; Sotorrios, L.; Marcos, M. L.; Choquesillo-Lazarte, D.; Biel, B.; Crovetto, L.; Gomez-Bengoa, E.; Gonzalez, M. T.; Martin, R.; Cuerva, J. M.; Campana, A. G. Versatile synthesis and enlargement of functionalized distorted heptagon-containing nanographenes. Chem. Sci. 2017, 8, 1068-1074.

(20) Yang, X.; Liu, D.; Miao, Q. Heptagon-embedded pentacene: synthesis, structures, and thin-film transistors of dibenzo[d, d'] benzo[1,2-a:4,5-a'] dicycloheptenes. Angew. Chem., Int. Ed. 2014, 53, 67866790.

(21) Kawai, K.; Kato, K.; Peng, L.; Segawa, Y.; Scott, L. T.; Itami, K. Synthesis and Structure of a Propeller-Shaped Polycyclic Aromatic Hydrocarbon Containing Seven-Membered Rings. Org. Lett. 2018, 20, $1932-1935$.

(22) Gu, X.; Li, H.; Shan, B.; Liu, Z.; Miao, Q. Synthesis, Structure, and Properties of Tetrabenzo[7]circulene. Org. Lett. 2017, 19, 22462249.

(23) Mughal, E. U.; Kuck, D. Merging tribenzotriquinacene with hexa-peri-hexabenzocoronene: a cycloheptatriene unit generated by Scholl reaction. Chem. Commun. 2012, 48, 8880-8882.

(24) Ip, H. W.; Ng, C. F.; Chow, H. F.; Kuck, D. Three-Fold SchollType Cycloheptatriene Ring Formation around a Tribenzotriquinacene Core: Toward Warped Graphenes. J. Am. Chem. Soc. 2016, 138, 13778-13781.

(25) Fernandez-Garcia, J. M.; Evans, P. J.; Medina Rivero, S.; Fernandez, I.; Garcia-Fresnadillo, D.; Perles, J.; Casado, J.; Martin, N. pi-Extended Corannulene-Based Nanographenes: Selective Formation of Negative Curvature. J. Am. Chem. Soc. 2018, 140, 17188-17196.

(26) Fujikawa, T.; Segawa, Y.; Itami, K. Laterally pi-Extended Dithia[6] helicenes with Heptagons: Saddle-Helix Hybrid Molecules. J. Org. Chem. 2017, 82, 7745-7749.

(27) Kawasumi, K.; Zhang, Q.; Segawa, Y.; Scott, L. T.; Itami, K. A grossly warped nanographene and the consequences of multiple oddmembered-ring defects. Nat. Chem. 2013, 5, 739-744.

(28) Dou, X.; Yang, X.; Bodwell, G. J.; Wagner, M.; Enkelmann, V.; Müllen, K. Unexpected phenyl group rearrangement during an intramolecular Scholl reaction leading to an alkoxy-substituted hexaperi-hexabenzocoronene. Org. Lett. 2007, 9, 2485-2488.

(29) Liu, J.; Narita, A.; Osella, S.; Zhang, W.; Schollmeyer, D.; Beljonne, D.; Feng, X.; Müllen, K. Unexpected Scholl reaction of 6,7,13,14-tetraarylbenzo[k]tetraphene: selective formation of fivemembered rings in polycyclic aromatic hydrocarbons. J. Am. Chem. Soc. 2016, 138, 2602-2608.

(30) Dötz, F.; Brand, J. D.; Ito, S.; Gherghel, L.; Müllen, K. Synthesis of large polycyclic aromatic hydrocarbons: variation of size and periphery. J. Am. Chem. Soc. 2000, 122, 7707-7717.

(31) Ormsby, J. L.; Black, T. D.; Hilton, C. L.; Bharat; King, B. T. Rearrangements in the Scholl oxidation: implications for molecular architectures. Tetrahedron 2008, 64, 11370-11378.

(32) Pradhan, A.; Dechambenoit, P.; Bock, H.; Durola, F. Twisted polycyclic arenes by intramolecular Scholl reactions of C3-symmetric precursors. J. Org. Chem. 2013, 78, 2266-2274.

(33) Di Giovannantonio, M.; Deniz, O.; Urgel, J. I.; Widmer, R.; Dienel, T.; Stolz, S.; Sánchez-Sánchez, C.; Muntwiler, M.; Dumslaff, T.; Berger, R.; Narita, A.; Feng, X.; Müllen, K.; Ruffieux, P.; Fasel, R. 
On-Surface Growth Dynamics of Graphene Nanoribbons: The Role of Halogen Functionalization. ACS Nano 2018, 12, 74-81.

(34) von Ragué Schleyer, P.; Maerker, C.; Dransfeld, A.; Jiao, H.; van Eikema Hommes, N. J. R. Nucleus-Independent Chemical Shifts: A Simple and Efficient Aromaticity Probe. J. Am. Chem. Soc. 1996, 118, 6317-6318.

(35) Corminboeuf, C.; Heine, T.; Seifert, G.; von Ragué Schleyer, P.; Weber, J. Induced magnetic fields in aromatic [n]-annulenesinterpretation of NICS tensor components. Phys. Chem. Chem. Phys. 2004, 6, 273-276.

(36) Lu, T.; Chen, F. Multiwfn: a multifunctional wavefunction analyzer. J. Comput. Chem. 2012, 33, 580-592.

(37) Zhang, X.-S.; Huang, Y.-Y.; Zhang, J.; Meng, W.; Peng, Q.; Kong, R.; Xiao, Z.; Liu, J.; Huang, M.; Yi, Y.; Chen, L.; Fan, Q.; Lin, G.; Liu, Z.; Zhang, G.; Jiang, L.; Zhang, D. Dicyclohepta[ijkl, uvwx] rubicene with Two Pentagons and Two Heptagons as a Stable and Planar Non-benzenoid Nanographene. Angew. Chem. 2020, 132, $3557-3561$.

(38) Oki, K.; Takase, M.; Mori, S.; Shiotari, A.; Sugimoto, Y.; Ohara, K.; Okujima, T.; Uno, H. Synthesis, Structures, and Properties of Core-Expanded Azacoronene Analogue: A Twisted pi-System with Two N-Doped Heptagons. J. Am. Chem. Soc. 2018, 140, 1043010434.

(39) Rempala, P.; Kroulik, J.; King, B. T. Investigation of the Mechanism of the Intramolecular Scholl Reaction of Contiguous Phenylbenzenes. J. Org. Chem. 2006, 71, 5067-5081.

(40) Zhai, L.; Shukla, R.; Wadumethrige, S. H.; Rathore, R. Probing the arenium-ion (protontransfer) versus the cation-radical (electron transfer) mechanism of Scholl reaction using DDQ as oxidant. J. Org. Chem. 2010, 75, 4748-4760.

(41) Krzeszewski, M.; Sahara, K.; Poronik, Y. M.; Kubo, T.; Gryko, D. T. Unforeseen 1,2-Aryl Shift in Tetraarylpyrrolo[3,2- b]pyrroles Triggered by Oxidative Aromatic Coupling. Org. Lett. 2018, 20, $1517-1520$.

(42) Dong, Y. Q.; Lam, J. W.; Tang, B. Z. Mechanochromic Luminescence of Aggregation-Induced Emission Luminogens. J. Phys. Chem. Lett. 2015, 6, 3429-3436.

(43) Kumar, R.; Aggarwal, H.; Srivastava, A. Of Twists and Curves: Electronics, Photophysics, and Upcoming Applications of Non-Planar Conjugated Organic Molecules. Chem. - Eur. J. 2020, 26, 1-24.

(44) Wang, C.; Li, Z. Molecular conformation and packing: their critical roles in the emission performance of mechanochromic fluorescence materials. Mater. Chem. Front. 2017, 1, 2174-2194.

(45) Qiu, Z.; Zhao, W.; Cao, M.; Wang, Y.; Lam, J. W. Y.; Zhang, Z.; Chen, X.; Tang, B. Z. Dynamic Visualization of Stress/Strain Distribution and Fatigue Crack Propagation by an Organic Mechanoresponsive AIE Luminogen. Adv. Mater. 2018, 30, No. 1803924.

(46) Sun, H.; Liu, S.; Lin, W.; Zhang, K. Y.; Lv, W.; Huang, X.; Huo, F.; Yang, H.; Jenkins, G.; Zhao, Q.; Huang, W. Smart responsive phosphorescent materials for data recording and security protection. Nat. Commun. 2014, 5, 3601.

(47) Janke, R. H.; Haufe, G.; Wurthwein, E.-U.; Borkent, J. H. Racemization Barriers of Helicenes: A Computational Study. J. Am. Chem. Soc. 1996, 118, 6031-6035.

(48) Barroso, J.; Cabellos, J. L.; Pan, S.; Murillo, F.; Zarate, X.; Fernandez-Herrera, M. A.; Merino, G. Revisiting the racemization mechanism of helicenes. Chem. Commun. 2018, 54, 188-191.

(49) Cruz, C. M.; Marquez, I. R.; Mariz, I. F. A.; Blanco, V.; Sanchez-Sanchez, C.; Sobrado, J. M.; Martin-Gago, J. A.; Cuerva, J. M.; Macoas, E.; Campana, A. G. Enantiopure distorted ribbon-shaped nanographene combining two-photon absorption-based upconversion and circularly polarized luminescence. Chem. Sci. 2018, 9, 39173924.

(50) Berezhnaia, V.; Roy, M.; Vanthuyne, N.; Villa, M.; Naubron, J. V.; Rodriguez, J.; Coquerel, Y.; Gingras, M. Chiral Nanographene Propeller Embedding Six Enantiomerically Stable [5]Helicene Units. J. Am. Chem. Soc. 2017, 139, 18508-18511.
(51) Liu, Z.; Lu, T.; Chen, Q. An sp-hybridized all-carboatomic ring, cyclo[18]carbon: Electronic structure, electronic spectrum, and optical nonlinearity. Carbon 2020, 165, 461-467. 